\title{
Epidermoid cyst of external auditory canal presenting as canal atresia: A rare case report
}

\author{
Jaimanti Bandhu Bakshi* and Anand Subash \\ Department of Otolaryngology and HNS, Postgraduate Institute of Medical Education and Research, Chandigarh, India
}

\begin{abstract}
We present the case of a 12-month-old male child who was brought to our hospital with complaints of left ear canal atresia. The child had normal hearing and development. Pre operative diagnosis of EAC atresia was made and atresioplasty was planned. During surgery, we found a cyst filling the EAC, which was obscuring the tympanic membrane, which was normal looking. Complete excision of cyst was done and it was reported as epidermal inclusion cyst. Child is on regular follow up with a normal looking EAC.
\end{abstract}

\section{Introduction}

Congenital aural atresia (CAA) has an incidence of 1 in 10,000 live births [1]. It is Bilateral in one third of the patients. CAA can be complete or incomplete. It is commonly associated with other congenital anomalies. The bone conduction is usually, but not always, normal in CAA.

Dermoid cysts are benign lesions that can occur anywhere in the body. They are most commonly found in testicles and ovaries. Around $7 \%$ are found in the head and neck region [1]. They are extremely rare in the EAC. It presents as canal obstruction and decreased hearing [2]. The cysts are termed as epidermoid when the lining presents only epithelium, dermoid cysts when skin adnexa are found, and teratoid cysts when other tissue such as muscle, cartilage, and bone are present [3]. Meyer in 1955 classified these cysts as true dermoid cysts, epidermoid cysts and teratoid cysts [4].

\section{Case report}

A 12-month-old Indian toddler was brought to our OPD with left ear canal atresia. The atresia was noted since birth. There were no complaints of decreased hearing as the other canal was patent. Family history was not significant and her mother had an uncomplicated delivery. On physical examination, the child was alert and left ear examination revealed a swelling in the left EAC completely obscuring the canal. Left pinna was normal except for the scarring around the tragus (Figure 1). HRCT temporal bone revealed EAC atresia with obliteration of cartilaginous part and soft tissue seen projecting into lateral aspect of left middle ear with tympanic membrane was not separately visible (Figure 2 and 3 ). Behavioral observational audiometry showed normal hearing. No other external facial or neck cysts, sinuses or lesions were noted and the examination of opposite ear was unremarkable. A provisional diagnosis of canal atresia was made and planned for atresioplasty under general anesthesia. Surgery was performed under general anesthesia on out patient basis, surgery was uneventful, and the patient recovery was good. The endaural incision was made and flaps raised and a cyst was present below the skin flap completely obstructing the canal (Figure 4). Attempt was made to remove the cyst along with its content in to; however, there was inadvertent tear of the cyst wall and cheesy content was extruded out. An intact canal was found after removal of the cyst, which was sent for histopathological examination. The tympanic membrane was normal. Macroscopically, the specimen was open cystic tissue piece measuring $4 \mathrm{~mm} \times 3 \mathrm{~mm} \times 2 \mathrm{~mm}$. Histopathological examination revealed a keratinizing stratified squamous epithelium with presence of granular cell layer. Adnexal structures were absent. Based on the above findings, epidermoid cyst was diagnosed. The infant made a full recovery (Figure 5).

\section{Discussion}

Epidermal inclusion cyst contains keratin fibers and are benign in nature [5]. Most commonly occurs in the skin and has a tendency to

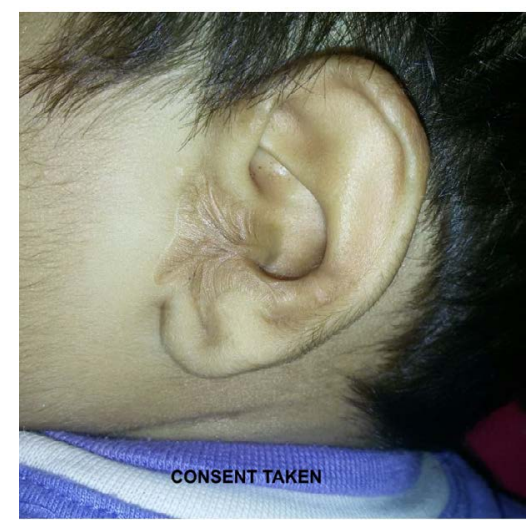

Figure 1. Clinical photograph of the left ear of child showing complete external auditory canal atresia.

Correspondence to: Dr. Jaimanti Bakshi, Additional Professor, Department of Otolaryngology and HNS PGIMER, Chandigarh, India; Tel: +911722756760, +919855827931; E-mail: drjayabakshi@ymail.com

Key words: canal atresia, epidermoid cyst, external auditory canal

Received: August 13, 2016; Accepted: September 26, 2016; Published: September 29, 2016 


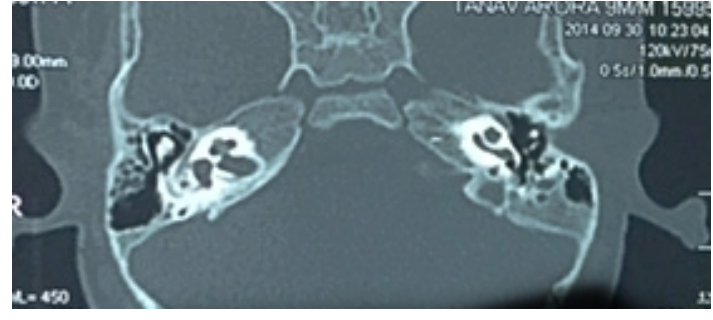

Figure 2. HRCT temporal bone showing normal middle ear cavity with ossicles.

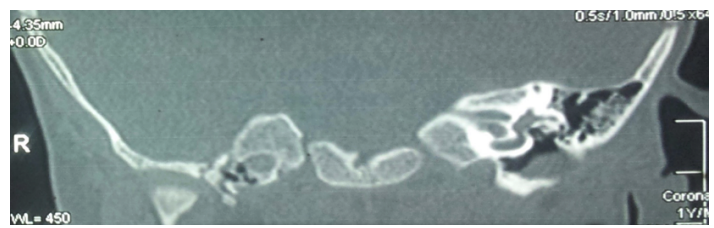

Figure 3. HRCT temporal bone coronal section showing sift tissue mass in left EAC.

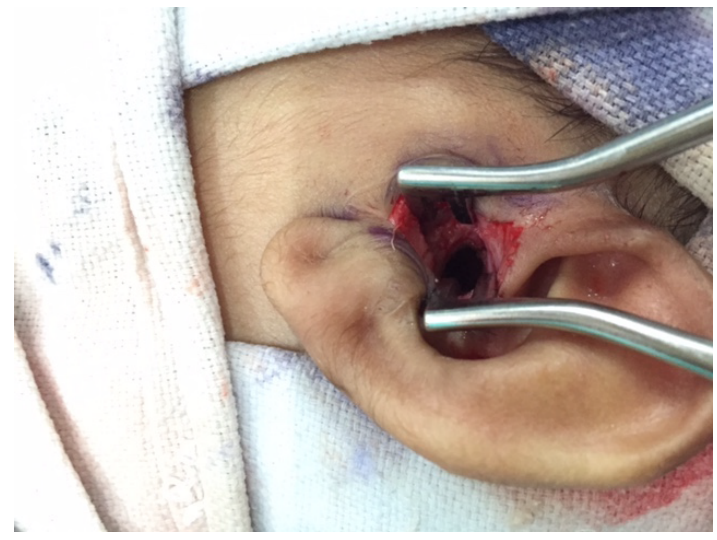

Figure 4. Intra-operative picture showing left meatoplasty.

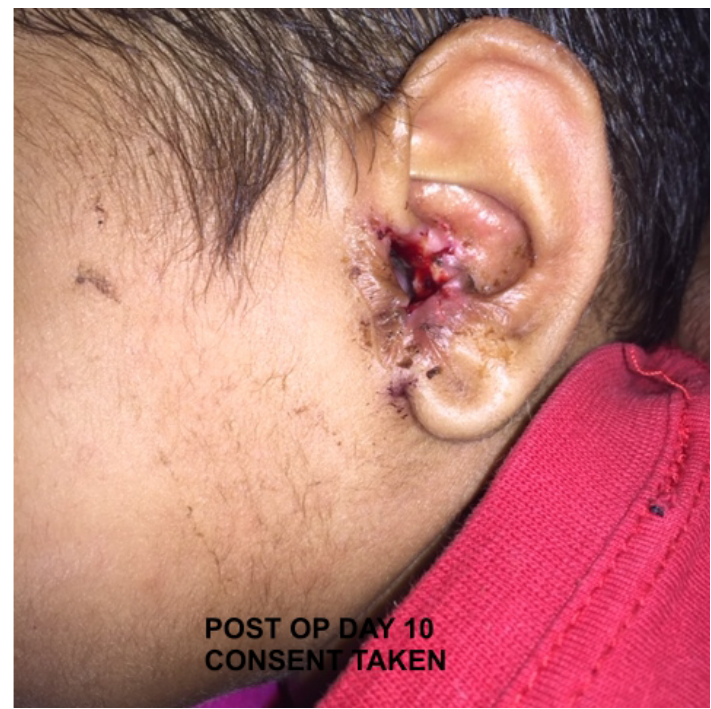

Figure 5. Clinical photograph at postop day 10 showing wide meatoplasty and well healing EAC. grow to the deeper epidermis. It is rarely seen in the EAC. Patients are mostly asymptomatic. They can get infected and later rupture. Epidermal inclusion cyst may mimic an early stage canal cholesteatoma which is consists of, hyper proliferative epithelium, keratin debris, an intact basement membrane, and accumulation of inflammatory cells. Surgery is the treatment in asymptomatic cases [6]. Several surgical approaches for removal of epidermoid cysts have been described. Complete removal of cyst along with the sac needs to be done to prevent recurrence. It is laborious and requires suture placements. Another technique, which is described, is the minimal excision technique, which is a less invasive and provides equally successful results. In this technique a 2- to 3-mm incision is made. The cyst contents and the cyst wall are removed through the small incision made. Active compression of the contents is required to facilitate removal of the contents and the sac. The tiny wound can be closed with a single suture. A variation of this technique a biopsy instrument is used to open the cyst instead of the small incision [7].

\section{Conclusion}

Epidermal inclusion cysts of EAC are rare and most patients remain asymptomatic. Surgery in this child was for cosmetic reasons. Complete excision of the cyst along with its sac prevents recurrence.

\section{References}

1. Suutarla S, Rautio J, Ritvanen A, Ala-Mello S, Jero J, et al. (2007) Microtia in Finland comparison of characteristics in different populations. Int J Pediatr Otorhinolaryngol 71: 1211-1217.[Crossref]

2. Abdel-Aziz M (2011) Epidermoid cyst of the external auditory canal in children diagnosis and management. J Craniofac Surg 22: 1398-1400.[Crossref]

3. Calderon S, Kaplan I (1993) Concomitant sublingual and submental epidermoid cysts a case report. J Oral Maxillofac Surg 51: 790-792.[Crossref]

4. Howell CJ (1985) The sublingual dermoid cyst. Report of five cases and review of the literature. Oral Surg Oral Med Oral Pathol 59: 578-580.[Crossref]

5. Alimoglu Y, Mercan H, Karaman E, Oz B (2010) Epidermal inclusion cyst of external auditory canal. J Craniofac Surg21: 1290-1291.[Crossref]

6. Erich J (1937) Dermoid cysts of the head and neck. Surg Gynecol Obstet 65:48-55.

7. Zuber TJ (2002) Minimal excision technique for epidermoid (sebaceous) cysts. $A m$ Fam Physician 65: 1409-1412, 1417-8, 1420.[Crossref]

Copyright: $\odot 2016$ Bakshi JB. This is an open-access article distributed under the terms of the Creative Commons Attribution License, which permits unrestricted use, distribution, and reproduction in any medium, provided the original author and source are credited. 